\title{
Lesões de pele em bovinos com doença granulomatosa sistêmica associada ao pastoreio de ervilhaca (Vicia spp.)
}

\author{
Skin lesions in cattle with systemic granulomatous disease associated to pasturing vetch (Vicia spp.)
}

\author{
Rafael Almeida Fighera ${ }^{1}$ Tatiana Mello de Souza ${ }^{1}$ Claudio Severo Lombardo de Barros ${ }^{2}$
}

\section{RESUMO}

\begin{abstract}
Descrevem-se as lesões cutâneas macroscópicas em 10 e histológicas em 8 vacas afetadas por doença granulomatosa sistêmica associada ao pastoreio de ervilhaca (Vicia spp.). Em todos os casos, as lesões cutâneas eram caracterizadas por múltiplas áreas coalescentes de alopecia, liquenificação e descamação. Os locais mais atingidos pela lesão de pele foram: cabeça e pescoço (10/10), tronco (4/10), períneo (3/10) e mama (2/10). Em todos os 8 casos avaliados histologicamente, as lesões se caracterizavam por dermatite perivascular superficial granulomatosa de intensidade variável. Outros achados histológicos incluíram dermatite perivascular profunda (1/8), perifoliculite (2/8), foliculite mural (3/8), hiperqueratose ortoqueratótica compacta (6/8), erosões (1/8), úlceras (2/8), microabscessos de Munro (8/8), crostas serocelulares (1/8), espongiose (4/8), degeneração hidrópica (5/8), acantólise (1/8), corpúsculos de Civatte (2/8), exocitose linfoplasmocitária (6/8), edema superficial (6/8), incontinência pigmentar (2/8), basofilia (6/8) e mineralização distrófica do colágeno (2/8), tumefação do núcleo das células endoteliais (8/8) e ectasia de glândulas sudoríparas (8/8).
\end{abstract}

Palavras-chave: doenças de bovinos, intoxicação por ervilhaca, intoxicação por Vicia spp., dermatite granulomatosa, dermatologia, patologia.

\section{ABSTRACT}

Gross and histopathological lesions in the skin of respectively 10 and 8 cows affected with systemic granulomatous disease associated with pasturing vetch (Vicia spp.) are described. In all cases, the cutaneous lesions were characterized by multiple coalescent areas of alopecia, lichenification and desquamation. More frequently affected sites were the skin covering the head and neck (10/10), trunk (4/10), escutcheon (3/10) and mammary gland (2/10). In all 8 histologically examined cases the lesions were characterized by superficial perivascular granulomatous dermatitis of varying intensity. Other histological findings included deep perivascular dermatitis (1/8), perifoliculitis (2/8), mural foliculitis (3/8), compact orthokeratotic hyperkeratosis (6/ $8)$, erosions (1/8), ulcers (2/8), Munro's microabscess (8/8), serocellular crusts (1/8), spongiosis (4/8), hydropic degeneration (5/8), acantholysis (1/8), Civatte bodies (2/8), lymphoplasmacytic exocytosis (6/8), superficial edema (6/8), pigmentary incontinence (2/8), basophilia (6/8) and collagen dystrophic mineralization (2/8), swollen nucleus of endothelial cells (8/8) and sweat gland ectasy (8/8).

Key words: diseases of cattle, vetch poisoning, Vicia spp. poisoning, granulomatous dermatitis, dermatology, pathology.

\section{INTRODUÇÃO}

A intoxicação por ervilhaca em bovinos é classificada em três formas clínicas (KELLERMAN et al., 1988). Uma delas se caracteriza por distúrbios nervosos agudos e morte após a ingestão das sementes de $\boldsymbol{V}$. cracca (MÜNCH 1914 apud FRÖHNER \& VÖLKER, 1950) e $\boldsymbol{V}$. villosa (CLAUGHTON \& CLAUGHTON, 1955). Em outra forma, descrita apenas em uma oportunidade, os bovinos afetados demonstram sinais clínicos predominantemente cutâneos (herpetiformes) (FRÖHNER \& VÖLKER, 1950). A terceira forma é a mais bem estudada das três e

\footnotetext{
${ }^{1}$ Médico Veterinário, aluno do Programa de Pós-graduação em Medicina Veterinária, área de concentração em Patologia Veterinária. Universidade Federal de Santa Maria (UFSM), 97105-900, Santa Maria, RS. E-mail: anemiaveterinaria@bol.com.br. Autor para correspondência.
}

${ }^{2}$ Médico Veterinário, PhD, Prof. Titular, Departamento de Patologia, UFSM. 
reconhecida nos Estados Unidos desde a década de 50 (KELLERMAN et al., 1988). Caracteriza-se clinicamente por dermatopatia, prurido, febre e queda na produção leiteira (PANCIERA et al., 1966); os bovinos afetados desenvolvem uma doença granulomatosa sistêmica, que pode afetar qualquer órgão, mas que é mais prevalente na pele, linfonodos, adrenal, baço, fígado, encéfalo, rim e coração (FIGHERA \& BARROS, 2004). Embora tanto na segunda quanto na terceira forma de apresentação da intoxicação por ervilhaca ocorra comprometimento cutâneo, o aspecto macroscópico e microscópico dessas lesões é distinto (FIGHERA \& BARROS, 2004).

As lesões de pele associadas à forma granulomatosa da intoxicação por ervilhaca variam com o estágio da doença (PANCIERA et al., 1966) e incluem dermatite papular, ulcerativa ou exsudativa (PANCIERA, 1978; BURROUGHS et al., 1983; PEET \& GARDNER, 1986; ODRIOZOLA et al., 1991; HARPER et al., 1993), espessamento cutâneo (PANCIERA, 1978; BURROUGHS et al., 1983), perda da elasticidade da pele (PANCIERA, 1978; BURROUGHS et al., 1983), pêlos ásperos (PANCIERA et al., 1966) e, por fim, alopecia (PANCIERA et al., 1966; ODRIOZOLA et al., 1991).

Com o passar do tempo, as lesões primárias desaparecem e são substituídas por exsudação (PANCIERA et al., 1966). O exsudato é amarelo-claro e flui através da superfície epitelial (PANCIERA et al., 1966; BURROUGHS et al., 1983). Após secar, o exsudato torna-se marrom-amarelado e dá origem a crostas (PANCIERA et al., 1966; KERR \& EDWARDS, 1982), que caem ou são arrancadas, formando erosões, úlceras ou fissuras na pele (PANCIERA et al., 1966; BURROUGHS et al., 1983). As lesões são acentuadamente pruriginosas (PANCIERA et al., 1966; KERR \& EDWARDS, 1982; BURROUGHS et al., 1983; HARPER et al., 1993) e induzem autotraumatismo, que causa ulceração cutânea (PANCIERA et al., 1966). Para a maior parte dos autores, essas lesões são distribuídas independentemente da pigmentação da pele (PANCIERA et al., 1966; HARPER et al., 1993), no entanto, em uma ocasião, as lesões foram descritas preferencialmente em regiões cutâneas pigmentadas (BURROUGHS et al., 1983). Nos bovinos que sobrevivem, as lesões de pele melhoram após cinco semanas (BURROUGHS et al., 1983; HARPER et al., 1993). Alguns bovinos podem apresentar prurido por longos períodos após a recuperação das lesões cutâneas (BURROUGHS et al., 1983).

Microscopicamente, as lesões cutâneas, à semelhança do que é visto em múltiplos órgãos, se caracterizam por infiltrado inflamatório constituído predominantemente por macrófagos epitelióides, linfócitos, plasmócitos, alguns eosinófilos e ocasionais células gigantes multinucleadas na derme (KELLERMAN et al., 1988). Além do infiltrado granulomatoso observa-se hiperqueratose leve (PANCIERA, 1978; BURROUGHS et al., 1983), pronunciada fibrose (BURROUGHS et al., 1983), acantose, espongiose, ulceração focal e formação de crostas serocelulares (HARPER et al., 1993). Nos casos mais graves, pode ocorrer infiltrado perivascular e perianexal composto por linfócitos, plasmócitos e alguns poucos macrófagos, associado ou não a edema e invasão da epiderme pelas células inflamatórias (PANCIERA, 1978; HARPER et al., 1993). Além disso, o infiltrado inflamatório pode invadir e preencher os folículos e as glândulas sebáceas e pode haver dilatação de glândulas sudoríparas (JOHNSON et al., 1992). Foram descritas lesões vasculares na pele caracterizadas por tumefação do núcleo das células endoteliais, espessamento e hialinização da parede de muitas arteríolas (PANCIERA, 1978; HARPER et al., 1993).

No único caso de reprodução experimental da intoxicação por ervilhaca, a pele foi avaliada em três intervalos de tempo e os achados encontrados incluíram edema dérmico e epidérmico, exocitose neutrofílica na epiderme e nos folículos, ulceração, formação de crostas, tumefação das células endoteliais, dermatite perivascular mista (linfócitos, plasmócitos, neutrófilos e eosinófilos), hidradenite e vasculite. As glândulas sudoríparas estavam dilatadas, com epitélio degenerado ou necrosado, e tinham seus lúmens obliterados por numerosas células inflamatórias (PANCIERA et al., 1992).

O objetivo deste trabalho foi descrever com detalhes os aspectos macroscópicos e histológicos das lesões de pele em bovinos afetados pela forma granulomatosa da intoxicação por ervilhaca no Brasil e discutir os principais diagnósticos diferenciais.

\section{MATERIAL E MÉTODOS}

Os dados epidemiológicos e clínicos foram obtidos durante duas visitas às propriedades afetadas e através de informações fornecidas pelos proprietários e veterinários de cada local onde ocorreram os surtos de intoxicação por ervilhaca. De 17 bovinos que morreram ou foram sacrificados, 10 foram necropsiados. Fragmentos de pele foram colhidos de 8 desses animais (região da cabeça e pescoço), fixados em formol a $10 \%$ e, mais tarde, processados rotineiramente para histologia, com coloração pela 
hematoxilina-eosina (HE). As diferentes lesões histológicas encontradas na pele foram descritas de acordo com a média da percepção subjetiva de dois patologistas.

Oito surtos de uma doença associada ao pastoreio de duas espécies de ervilhaca (predominantemente Vicia villosa e, em menor grau, V. sativa) foram observados de setembro a novembro de 2001 e, em agosto de 2002, em bovinos da região noroeste do Rio Grande do Sul. Nesses 8 surtos, 17 animais morreram espontaneamente ou foram sacrificados e 10 foram necropsiados. Todos os bovinos afetados eram fêmeas, Holandês ou cruza Holandês e Jersey, com idades que variavam de cinco a 12 anos. Os estabelecimentos onde ocorreram os surtos eram pequenas propriedades leiteiras e a produção média diária dessas vacas oscilava de seis a 24 litros. Os municípios afetados foram Santa Rosa (três surtos), Tuparendi, Giruá, Campo Novo, Braga e Salvador das Missões (um surto em cada).

\section{RESULTADOS E DISCUSSÃO}

Em todos os casos, as lesões cutâneas eram caracterizadas por múltiplas áreas coalescentes de alopecia, liquenificação e descamação, que davam um aspecto enrugado à pele da cabeça e do pescoço. Em seis dos 10 bovinos afetados, havia escoriações e exsudação associadas à lesão de pele. Isso ocorria principalmente pelo traumatismo auto-infligido em decorrência do intenso prurido. Alguns bovinos coçavam-se contra objetos e outros mordiam as áreas afetadas. Os locais mais atingidos pela lesão de pele foram: cabeça e pescoço (10/10), tronco (4/10), períneo (3/10) e mama (2/10).

Microscopicamente, em todos os casos avaliados, as lesões se caracterizavam por infiltrado inflamatório constituído de macrófagos epitelióides, linfócitos e plasmócitos. Células gigantes multinucleadas compuseram o infiltrado em alguns casos (4/8), eosinófilos, neutrófilos e fibroblastos foram vistos em poucos casos (2/8, 1/8 e 1/8 respectivamente). Esse infiltrado inflamatório tinha grau variável de severidade (leve a acentuado) e localizava-se sempre ao redor dos vasos sangüíneos superficiais (8/8) (Figura 1A), mas em uma vaca era possível notar abundante quantidade de células inflamatórias na derme profunda. Nessa região, fibras colágenas mineralizadas podiam ser vistas sendo fagocitadas por células gigantes multinucleadas. Em alguns casos, além da dermatite perivascular, havia perifoliculite (2/8) (Figura 1B) ou foliculite mural (3/ 8) (Figura 1C).
$\mathrm{Na}$ maioria dos casos (6/8), havia um espessamento das camadas do estrato córneo por corneócitos anucleados (hiperqueratose ortoqueratótica compacta) (Figura 1D). Erosões e úlceras (Figura 1E) podiam ser notadas em apenas algumas amostras (1/8 e 2/8, respectivamente). Acúmulos de neutrófilos dessecados entre queratinócitos de qualquer estrato epidérmico (microabscesso de Munro), mas predominantemente entre os corneócitos (Figura $1 \mathrm{~F}$ ), podiam ser vistos em todos os casos. Em apenas um dos animais, essas pústulas estavam rompidas e recobertas por material eosinofílico e exsudato celular ressecado (crosta serocelular).

Acúmulo de líquido entre os queratinócitos de todos os estratos, causando perda do contato entre as células (espongiose) (Figura 1G), podia ser visto em $4 / 8$ casos e acúmulo de líquido intracelular (degeneração hidrópica), em queratinócitos do estrato basal, ocorreu em 5/8 casos. Em um dos bovinos afetados, a degeneração hidrópica resultou em perda da coesão (acantólise) entre os queratinócitos (Figura $1 \mathrm{H})$. Outras lesões epidérmicas incluíram aumento na quantidade de figuras apoptóticas no estrato basal (corpúsculos de Civatte) (2/8) (Figura 1I) e epiteliotropismo variável (6/8), visto como invasão da epiderme por células inflamatórias, principalmente linfócitos e plasmócitos (exocitose).

$\mathrm{Na}$ derme, além da inflamação granulomatosa ao redor dos vasos sangüíneos e anexos, havia edema superficial (6/8) (Figura 1J) e acúmulo de macrófagos carregados de pigmento marrom-dourado, compatível com melanina (incontinência pigmentar) (2/8) (Figura 1L). Em 6/8 casos, o colágeno dérmico demonstrava variável basofilia (Figura 1M), que em $2 / 8$ casos assumia um padrão flocular (mineralização distrófica do colágeno) (Figura 1N). Tumefação nuclear das células endoteliais (Figura 1O) e ectasia de glândulas sudoríparas (Figura 1P) foram observadas em todos os casos.

As lesões macroscópicas vistas na pele dos bovinos deste estudo são semelhantes às descritas por outros autores. No entanto, a distribuição das lesões diferiu grandemente. Dos 10 animais ora relatados, as lesões foram muito mais prevalentes na cabeça e no pescoço (100\% dos casos) do que no tronco $(40 \%)$, períneo (30\%) e mama (20\%). Alguns autores afirmam que as lesões ocorrem principalmente no períneo, úbere, cauda e pescoço (PANCIERA et al., 1966) e que, após algum tempo, aparecem na cabeça, tronco e membros (PANCIERA et al., 1966; KERR \& EDWARDS, 1982). Em outros surtos descritos na literatura, as lesões iniciaram na base da cauda e 


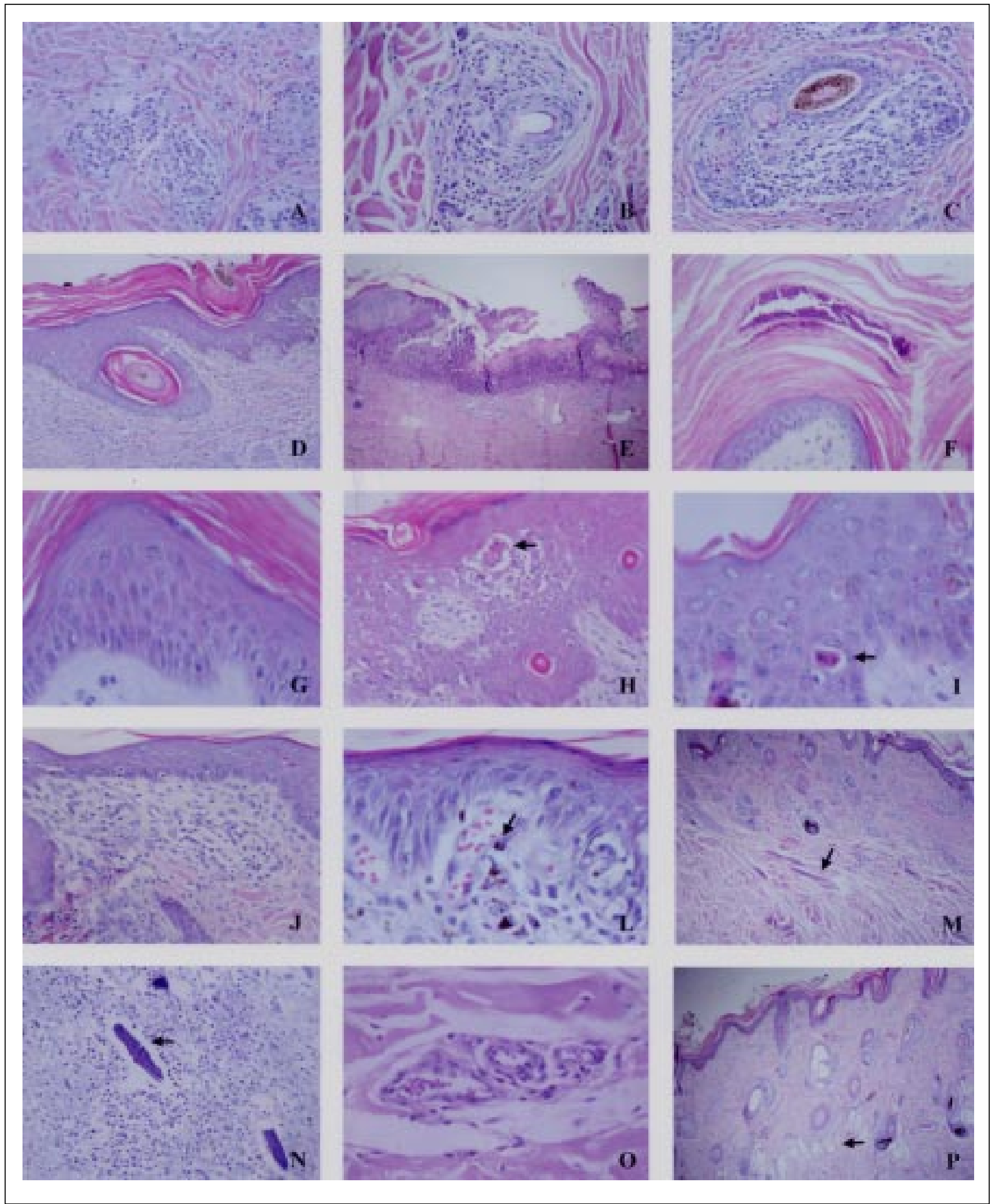

Figura 1 - Prancha com as principais lesões histológicas encontradas na pele dos bovinos com doença granulomatosa sistêmica associada ao pastoreio de ervilhaca (Vicia spp.). A) Dermatite perivascular superficial granulomatosa; B) perifoliculite granulomatosa; C) foliculite mural granulomatosa; D) hiperqueratose ortoqueratótica compacta; E) úlcera; F) microabscesso de Munro; G) espongiose; H) acantócitos (seta) no interior de uma fenda epidérmica (acantólise); I) corpúsculo de Civatte (seta); J) edema dérmico superficial; L) macrófagos carregados de melanina (seta) caracterizando incontinência pigmentar; M) basofilia das fibras de colágeno (seta); N) fibra de colágeno basofílica e de aspecto flocular (seta) (mineralização distrófica do colágeno); O) tumefação do núcleo das células endoteliais; e P) ectasia de glândulas sudoríparas (seta). 
pescoço, posteriormente espalhando-se para o tronco e membros (KERR \& EDWARDS, 1982) ou se manifestaram inicialmente na cabeça, períneo, cauda e úbere, sendo vistas no pescoço, tronco e membros, após alguns dias (BURROUGHS et al., 1983). Num surto em touros na Argentina, apenas a pele da cabeça e do peito foi afetada (ODRIOZOLA et al., 1991). Nos casos aqui descritos, as lesões evoluíram ao mesmo tempo nas diferentes localizações e, além de mais prevalentes, foram sempre mais graves na cabeça e pescoço.

Microscopicamente, as lesões cutâneas foram também muito semelhantes às descritas por outros autores (KELLERMAN et al., 1988; PANCIERA et al., 1992), principalmente no que diz respeito ao tipo de infiltrado inflamatório e sua localização na derme. Todos os bovinos avaliados apresentaram dermatite perivascular superficial, que variou de leve a acentuada. Dermatite perifolicular e foliculite mural foram também observadas, à semelhança do que é descrito em outros relatos (JOHNSON et al., 1992). Hiperqueratose (PANCIERA, 1978; BURROUGHS et al., 1983), edema dérmico e epidérmico (PANCIERA et al., 1992), dilatação de glândulas sudoríparas (JOHNSON et al., 1992), exocitose linfoplasmocitária (PANCIERA, 1978; HARPER et al., 1993), acantose, espongiose, erosão/ulceração focal e formação de crostas serocelulares (HARPER et al., 1993) relatadas em outros surtos foram também lesões observadas neste trabalho.

Com exceção da tumefação do núcleo das células endoteliais, não foram encontradas lesões vasculares na pele de nenhum dos bovinos afetados, que, conforme alguns autores, podem ser vistas sob a forma de espessamento e hialinização da parede de muitas arteríolas (PANCIERA, 1978; HARPER et al., 1993) ou até mesmo como vasculite (PANCIERA et al., 1992). Todos os bovinos avaliados apresentavam tumefação do núcleo das células endoteliais, o que também tem sido descrito pelos mesmos autores (PANCIERA, 1978; HARPER et al., 1993). No entanto, na nossa rotina de dermatopatologia bovina, tumefação do núcleo das células endoteliais é um achado freqüente em peles normais, o que põem em dúvida o significado dessa alteração. Fibrose dérmica, descrita em um bovino de um surto (BURROUGHS et al., 1983), também não foi por nós encontrada.

Outro achado importante diz respeito à ausência de alterações nas glândulas sudoríparas de todos os bovinos avaliados. Segundo alguns autores, os túbulos das glândulas sudoríparas mostram-se degenerados ou necrosados (PANCIERA et al., 1992).
Como as células epiteliais das glândulas sudoríparas são as primeiras a sofrer autólise, é possível que as alterações vistas pelos autores no passado constituam apenas artefato pós-morte.

Várias outras alterações cutâneas importantes como microabscesso de Munro, degeneração hidrópica, acantólise, corpúsculos de Civatte, incontinência pigmentar, basofilia do colágeno e mineralização distrófica do colágeno, que até então não haviam sido descritas em associação com a intoxicação por ervilhaca, foram encontradas na pele de alguns dos animais deste estudo.

As lesões de pele em todos os surtos aqui descritos são macroscopicamente muito semelhantes à dermatofitose, que deve ser considerada no diagnóstico diferencial da doença clínica. $\mathrm{O}$ aspecto macroscópico e a distribuição das lesões em diferentes locais da pele podem ser praticamente idênticos aos casos de intoxicação por ervilhaca. Isso pode ser ilustrado pelo fato que um dos surtos aqui descritos foi primeiramente interpretado pelos clínicos como dermatofitose. A diferenciação pode ser feita pelo restante dos achados clínicos (febre, queda na lactação, etc...), que não ocorrem nas micoses cutâneas, pela epidemiologia e pela avaliação histológica. Epidemiologicamente, lesões ocasionadas por dermatófitos (principalmente por Trichophyton mentagrophytes) afetam bovinos jovens (EDWARDSON, 1979), ao contrário do que é visto na intoxicação por ervilhaca. Na histologia, lesões ocasionadas por dermatófitos caracterizam-se por dermatite perifolicular, foliculite ou furunculose associada a imagens negativas de hifas ou artrosporos levemente basofílicos. Nesses casos, colorações pela prata (coloração de metenamina-nitrato de prata de Gomori - GMS) ou pelo ácido periódico de Schiff (PAS) são úteis para melhor visualizar o fungo (WRIGHT \& ALLINGHAM, 1976).

Outros diagnósticos diferenciais para a lesão cutânea associada à ingestão de ervilhaca devem incluir sarna sarcóptica (Sarcoptes scabiei var. bovis), psoróptica (Psoroptes natalensis), corióptica (Chorioptes bovis) e demodécica (Demodex bovis), besnoitiose (Besnoitia besnoiti), fotossensibilização, urticária, deficiência de zinco, linfossarcoma esporádico (forma cutânea) e certas formas ("mela" ou "chorona") de dermatofilose (Dermatophilus congolensis). Nesses casos, a diferenciação poderá ser feita pelo histórico do rebanho, tipo de lesão cutânea, distribuição das lesões, presença ou ausência de outros sinais clínicos e histologia.

As lesões granulomatosas na pele, e concomitantemente em outros órgãos, constituem uma 
característica histológica bastante distinta da intoxicação por ervilhaca e quando associadas aos dados epidemiológicos permitem o diagnóstico da toxicose (PANCIERA et al., 1992). Esses dados são o pastoreio da planta por mais de duas semanas (geralmente acima de seis semanas), tratar-se de bovinos da raça Holandês ou Angus acima de três anos de idade, uma morbidade variável (1-68\%) e uma letalidade de $50 \%$ a $100 \%$ (KELLERMAN et al., 1988). No entanto, lesões histológicas granulomatosas sistêmicas podem ser observadas em outras doenças semelhantes que ocorrem em bovinos sem acesso à ervilhaca. Essas condições passaram a ser conhecidas como "doenças semelhantes à intoxicação por ervilhaca" (PANCIERA et al., 1992) ou, como são denominadas na Europa, "síndrome de prurido, pirexia e hemorragia" (MATTHEWS \& SHREEVE, 1978). Essas doenças são clínica e histologicamente muito semelhantes à intoxicação por ervilhaca e ocorrem principalmente em vacas de leite que recebem silagem ou concentrado durante o inverno. Elas incluem uma condição descrita no Reino Unido e associada ao consumo de silagem contendo o conservante químico comercial Sylade (MATTHEWS \& SHREEVE, 1978); uma doença relatada na Holanda em bovinos que recebiam ração contendo diuriedo-isobutano (DUIB) (BREUKINK et al., 1978); e a intoxicação por polpa cítrica (GAVA \& BARROS, 2001). Essa última enfermidade tem sido descrita em bovinos no Brasil desde 1996 (GAVA et al., 1996) e as lesões de pele e viscerais são morfologicamente muito semelhantes à intoxicação por ervilhaca. As hemorragias encontradas na intoxicação por polpa cítrica, no entanto, não são vistas na doença granulomatosa sistêmica associada ao pastoreio de ervilhaca e os dados epidemiológicos permitem o diagnóstico diferencial. É possível que exista um princípio químico comum a todas essas condições (GAVA \& BARROS, 2001).

\section{CONCLUSÕES}

As alterações macroscópicas e histológicas da pele dos bovinos são, até certo ponto, semelhantes às descritas por outros autores. No entanto, foram observadas outras lesões que podem auxiliar no diagnóstico clínico-patológico da intoxicação por ervilhaca no animal vivo, principalmente quando a inflamação granulomatosa não é grave o suficiente para caracterizar a doença.

\section{REFERÊNCIAS BIBLIOGRÁFICAS}

BREUKINK, H.H. et al. Pyrexia with dermatitis in dairy cows. Vet Rec, v.103, p.221, 1978.
BURROUGHS, G.W. et al. Suspected hybrid vetch (Vicia villosa crossed with Vicia dasycarpa) poisoning of cattle in the Republic of South Africa. J South Africa Vet Assoc, v.54, p.75-79, 1983 .

CLAUGHTON, W.P.; CLAUGHTON, H.P.L. Vetch seed poisoning. Auburn Vet, v.10, p.125-126, 1955.

EDWARDSON, J. An outbreak of ringworm in a group of young cattle. Vet Rec, v.104, p.474-477, 1979

FIGHERA, R.A.; BARROS, C.S.L. Systemic granulomatous disease in Brazilian cattle grazing pasture containing vetch (Vicia spp). Vet Hum Toxicol, v.46, p.62-66, 2004.

FRÖHNER, E.; VÖLKER, R. Lehrbuch der toxikologie für tierärzte. 6.ed. Stuttgart : Ferdinand Enke, 1950. 253p.

GAVA, A.; BARROS, C.S.L. Intoxicação por polpa cítrica. In: RIET, F.C. et al. Doenças de ruminantes e eqüinos. São Paulo: Varela, 2001. p.212-215.

GAVA, A. et al. Síndrome pirético-hemorrágica-pruriginosa em bovinos, Lages, SC, 1996. In: ENCONTRO DE LABORATÓRIOS DE DIAGNÓSTICO VETERINÁRIO DO CONE SUL, 1., 1996, Campo Grande, MS. Anais... Campo Grande : UFMS, 1996. V.1, 310p. p.129.

HARPER, P.A. et al. Vetch toxicosis in cattle grazing Vicia villosa ssp dasycarpa and V. benghalensis. Aust Vet J, v.70, p.140-144, 1993.

JOHNSON, B. et al. Systemic granulomatous disease in cattle in California associated with grazing hairy vetch (Vicia villosa). J Vet Diag Invest, v.4, p.360-362, 1992

KELLERMAN, T.Z. et al. The skin and adnexa. In: Plant poisonings and mycotoxicoses of livestock in Southern Africa. Cape Town : Oxford University, 1988. Cap.8, p.215225 .

KERR, L.A.; EDWARDS, W.C. Hairy vetch poisoning of cattle. Vet Med Small Anim Clin, v.77, p.257-258, 1982.

MATTHEWS, J.G.; SHREEVE, B. Pyrexia/pruritis/haemorrhagic syndrome in dairy cows. Vet Rec, v.103, p.408-409, 1978.

ODRIOZOLA, E. et al. An outbreak of Vicia villosa (hairy vetch) poisoning in grazing Aberdeen Angus bulls in Argentina. Vet Hum Toxicol, v.33, p.278-280, 1991.

PANCIERA, R.J. Hairy Vetch (Vicia villosa Roth) poisoning in cattle. In: KEELER, R. F. et al. Effects of poisonous plants on livestock. New York : Academic, 1978. p.555-563.

PANCIERA, R.J. et al. A disease of cattle grazing hairy vetch pasture. J Am Vet Med Assoc, v.148, p.804-808, 1966.

PANCIERA, R.J. et al. Hairy vetch (Vicia villosa Roth) poisoning in cattle: update and experimental induction of disease. J Vet Diag Invest, v.4, p.318-325, 1992.

PEET, R.L.; GARDNER, J.J. Poisoning of cattle by hairy or wooly-pod vetch, Vicia villosa subespecies dasycarpa. Aust Vet J, v.63, p.381-382, 1986.

WRIGHT, A.I.; ALLINGHAM, R. Letter: diagnosing ringworm. Vet Rec, v.98, p.411-412, 1976. 